\title{
DISCLAIMISR
}

This report was prepared as an scoont of wot spowored by an spacy of the United Stateo

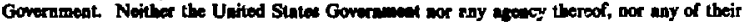

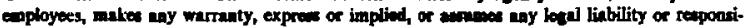
bility for the scewracy, completencen, oz uefulnew of any ifformation, apparatus, product, or proceses diefloed, or represeats that it une would ont infringe privately owned rights. Reference herein to any epecific commercial product, process, or ervice by trade name, tradenark, manufacturer, or otberwise does not ecceusily contitute or imply its endorwenent, recommendation, or favoring by the United States Goverament or any agency thereof. The views and opinions of authors expreaned herein do not necestarily state or reflect thone of the United Statea Goverument or any apency thereaf.

\section{SUPPRESSION OF PROPAGATING TE MODES IN THE FNAL ANTIPROTON SOURCE STOCHASTIC BEAM COOLING SYSTEM*}

Walter C. Barry

LBL- -18797

DE85 016559

\author{
Lawrence Berkeley Laboratory \\ University of California \\ Berkeley, CA 94720
}

May 1985

- This work was supported by the Director, Office of Energy Research, Office of High Energy and Nuclear Physics, High Energy Physics Division, U.S. Dept. of Energy, under Contract No. DE-ACD3-76SFOOO98. 


\author{
Walter C. Barty \\ Lawrence Barkaloy Leboratory \\ Univaralty of Callfomia \\ Barkeley, Californla $\$ 720$
}

\section{Abarnat}

A method of attenuating the propagation of waveguide modes in the atoctratic cooling erray beam pipet to be utilized in the eccumulator end dabuncher rings of the Formilab sediproton source is dexaribed. The attenuntion method treated involves lining the vertical walls of the beam pipes with a ferrimagnetic material. The gemeral solution for propegation in a norhomogeneously loaded waveguide is presented along with numerical rexults specific to the antiproton source beam cooling system. Also desctibed is a broscband, sutomated tochnique for the simultaneous menturement of complex 4 and $c$ developed to aid in the choracterization of different ferrite materials. Permittivity and permeability data for a typical ferrite is presented along with a discussion of the effects of these parameters on waveguide morde attenuation in the ferrite lined beam pipes.

\section{Introduction}

Thia peper addreases the problem of attementing the propegation of waveguido modes in the stochantic cooling erray beam plpes to be utilized in the accumuleter and debunctier rings of the FNAL i source. I The rectangular geometries of both the $1-2 \mathrm{CHz}$ and $2-4 \mathrm{CHz}$ array beam pipes allow propogation of the $T E_{10}, T E_{20}$. $T E_{30}$ and $T E_{40}$ modes within the operating band of each pipe. These weveguide modes propegata with a velocity comparable to that of the beam and can induce fales signals on the array pickups thereby raiaing the overall noise lavel in the system. The method treated here for atterwating these waveguide modes involves lining the vertical walls of the beam pipes with a ferrimagnetic material of complex permittivity and permeability (c and $\mu$ ). The decision to employ ferrite as the attanuating material was based on ite excellent RF attenuating properties, vacuum compatibiliky, and availability.

The general solution for propagation in a nonhomogeneously loaded waveguide is dexcribed along with a broadband, automated technique for simultaneously messuring the complex $c$ and $y$ of a given ferrite ample. This measurement technique was developed to characterize accurately the etectromagnetic properties of the several different ferrites under consideration for the attenuation application. By using the c and $n$ data measured by this technique in conjunction with the loaded waveguide analysis, the atlenvation of TE modes in a beam pipe lined with a given ferrite could be predicted. On this basis a particular ferrite was chosen to tina a $2-4 \mathrm{CHz}$ array to be installed in tive debuncher ting of the $p$ source. Future experiments to determine the effect of this loaded array on noise levels in the debuncher are anticipated.

\section{Mode Anulyais of Loaded Berm Pige}

Figure I depicts the cross extion of a weveguide (beam pipe) loaded with two slabs of forrimagretic material (regions II and IV) of thickness $t_{2}$. The slabs are parallel to the direction of propagation ( $z$ ) and at alstance $t_{1}$ from asch vertical wall. Regione $l$, III and $V$ are aseumed to be free spece while regions II and iv have complex permittivities and permeabilities of the form:

$$
c=c^{\prime}-j c^{*} \quad \mu=u^{\prime}-j \mu^{n}
$$

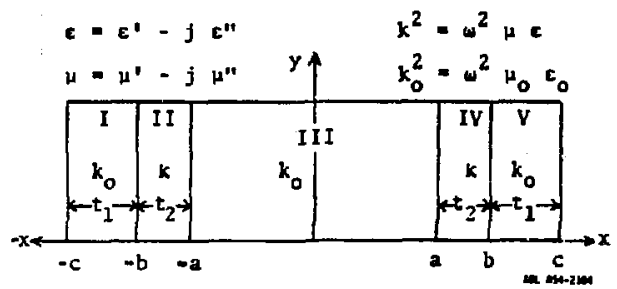

Fig. 1. Farrite Lceded Waveguide Ceometry

The gosi of the salyals is to cotermine the stemuating offect of the ferrite for the different modes thot may bo precent in the gulde. Some inalght into the optionum plecement of the ferrita for maximum attanuation to do desired. By solving the boundery value problem for the louded guidn, the elgenvalue equation that govern the propegation conutunts of the odd and oven modet in the guide can be obtained. The attenuatlon of a given mode is then related to the real part of its propsegation constant. Because of the length of the analyais, only the pertinent resulte, the odd and oven elgonvalus equations, are presented below. The detailed boundary value enalysis may be found in reference [2].

The eigenvalue equations presented are valid for odd and even TE modes with no field veriations with the $y$ coordinate. This condition is satisfied for frequencied lets than $5 \mathrm{GHz}$ for both the $1-2 \mathrm{6Hz}$ and $2-4 \mathrm{CHz}$ errays whose $x, y$ dimensions are $30 \mathrm{~cm}, 3 \mathrm{~cm}$ and $15 \mathrm{~cm}, 3 \mathrm{~cm}$ respectively. The equations are:

$$
\begin{aligned}
& \mu_{0} \& \tan \left(p t_{1}\right)\left[\mu_{0} \ell \tan \left(2 t_{2}\right)+\mu p \tan (p a)\right] \\
&=\mu p\left[\mu_{0} \ell-u p \tan \left(l t_{2}\right) \tan (p a)\right] \text { Even modes } \\
& \mu_{0} \& \tan \left(p t_{1}\right)\left[\mu p+\mu_{0} \ell \tan (p a) \tan \left(2 t_{2}\right)\right] \\
&=\mu_{\nu}\left[\mu p \tan \left(\varepsilon t_{2}\right)-\mu_{0} l \tan (p a)\right] \text { Dod nodes }
\end{aligned}
$$

where:

$$
\begin{aligned}
& 2=\sqrt{p^{2}+k^{2}-k_{o}^{2}} \\
& k=\omega \sqrt{\mu c}
\end{aligned}
$$

Complex wave number in loaded regions

p Complex eigenvalue for a given mode (analogoul to cutoff wave number $k_{c}$ for an unloadad guida)

$t_{1} \cdot t_{2} \cdot a$

Dilnensiona as defined in Fig. 1 
The ettenuation of a mode with elganralue $p$ is then given oy:

$$
(d) / m)=0.686 \operatorname{Re}\left[r\left(m^{-1}\right)\right]
$$

whers:

$$
Y=\sqrt{\phi^{2}-k_{0}^{2}} \quad \begin{aligned}
& \text { Complex propagation } \\
& \text { content }
\end{aligned}
$$

The even and odd modes of (1) and (2) refer to field iymmetry bout $x=0$, l.e. $\psi(x)-\psi(-x)$ for even modes and $\psi(x)=-\psi(-x)$ for odd modes. The dominant mode is the even mode with the smallest value of $p$ allowed by (1) and is attenuated the least. Given the physical dimensions

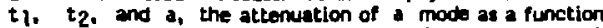
of frequency may be computed by solving (1) or (2) numerically provided $c$ and $\mu$ are known ovar the bend of interast. In ordar to dotermine $f$ and $\mu$ as a function of frequency for a given smple of ferrite, the measurement tectnique descrised below was developed.

\section{Mesurement Technigue for. E. and}

The general technique for datermining $e$ and involves meanuring the complex $S$ parameters for a waveguide or tranemission line loaded with the material under teat. The technique described hare employs a strip trenemiselon line fixture thown in Fig. 2 inte which blocke of the material to be mesured may be ineerted easily. An automated network analyzer system is used to make frequency-swept S-parameter measurements of the loadind stripline fixture. Values for $c$ and $y$ may then be calculated from the $S$ parameters.

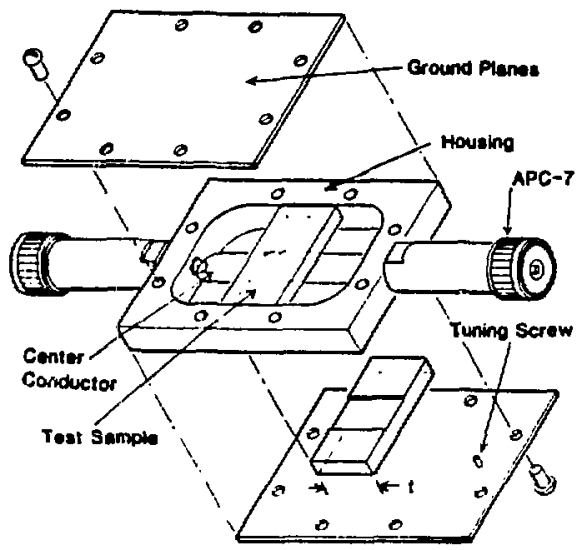

1Et sa..ivt

Fig. 2. Stripline Teat Fixture for Measuring $c$ and $\mu$

Referring to Fig. 2, an unknown sample material of physical length $t$ is claced in the center of the atrip transmission line fixture whose unloaded terminal to terminal olectricial iength is $2 L+t$. For this configuration it can be shown thit the complex $f$ and $u$ of the sarnole are related to the 5 parametern freawred at the terminats of the fixture by uve following equations: 3

$$
\begin{gathered}
c_{r}=\frac{k}{k_{0}}\left(\frac{1-R}{1+R}\right) \\
u_{r}=\frac{k}{k_{0}}\left(\frac{1+R}{1-R}\right) \\
k=\frac{1}{t} \cos ^{-1}\left(\frac{e^{-j 4 k_{0} L}+s_{12}^{2}-s_{11}^{2}}{22^{-j 2 k_{0} L} s_{12}}\right) \\
R=s_{11}\left(e^{-j 2 k_{0} L}-s_{12} e^{-j k t}\right)^{-1}
\end{gathered}
$$

It chould be noted that when using the sbove equations the length of the exmple should be lase then $2, / 2$, in order to avoid dimensional rusonences ( $\lambda_{n}$ is weveliength intide the sample materiab). For this case the principal brench of the inverse coine function in (6) may be uncd.

The sccuracy of the measurement technique depends grently on three major factors; the quality of the atripline to cosx match in the fixture, the match of the stripline to the network andyzer $(5084$ and the accuracy of the 5-parameter maxurements. The first two factors depend on the constructlon and fine uning techniques for the fixture, the details of which may be found in reference [3]. The S-parameter measurements were performed with a Hewlett-Peckard network analyzer system, the main components of which are an $8410 \mathrm{C}$ netwock analyzer, 87468 5-parameter test set and an Balla harmonic froquency converter. An HP-sal6 computer with appropriate interfacing and peripherals was used for automation, data acquisition, computation and printing/plotting.

For the purpose of ascessing the validity of the ineosurement tectnique three dielectrics with well known properties - teflon, lucite and polyeihylenc--were measured over the .5-5.5 6Hz bend. The meanured values of ". for the three materials were found to be within better than $\pm 5 \%$ of the generally accepted values of $2.10,2.26$ and 2.60 respectively. As would be expected, $u^{\prime}=1$ was measured in all three cases. For low loss materials uch as

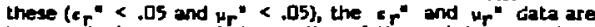
inaccurdite because of the quality of the matches described above. ${ }^{3}$ However, the meaurement Lechnique in general was found to be eccurate to within better than $\pm 5 \%$ for ali cases of $c_{r}$ and $\mu_{r}$ excluding $c_{r}$ " and $\mu_{r}$ "leas than .05 .

\section{Ferrite Mexurements and Attenuation Data for the 2-4 CHHz Array}

The permittivity and permeability of five different ceramic ferrites were maseured over the $.5-5.5 \mathrm{6Hz}$ band using the above technique. The attenuation afforded by each type of ferrite inside a 2-4 CHz array beam pipe was then evaluated using Eqs. (1), (2) and (3). Figure 3 shows the relative permittivity and permeabillty of Emerson and Cuming NZ-5I ceramic ferrite tiles, measured as a function of frequency. The data in F:2. 3 are typical of all the fernite samples that were evaluated. The similarity of the $c_{r}$ and $u_{r}$ data for the different ferrites is attributed to the fact that they are all ceramic componitions of spinal type forrites with only slightly different mixture formules. Any variation in $c_{r}$ and $M r$ among the dlfferenc semples had a negligible effect on atfenution in the 2-4 GHz array. Hence, based on its easy availability, NZ-51 was chosen to line the array. 


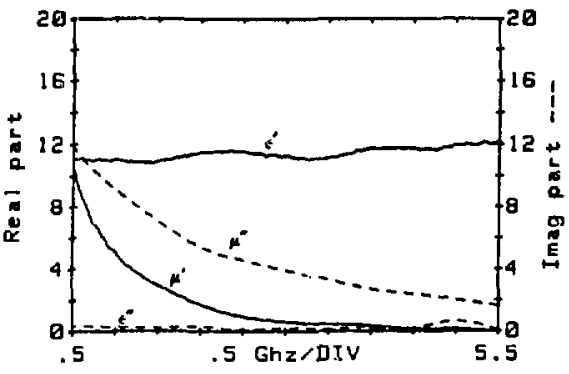

14:40-2103

Fig. 3. Ralative Permittivity and Permanbility of NZ-51

The NZ-51 tiles used in the $2-4 \mathrm{GHz}$ array are $.5 \mathrm{~cm}$ thick, i.e. $t_{2}=.5 \mathrm{~cm}$ in Eqs. (1) and (2). Figure 4 shows the atternation predictexl by Eqs. (1), \{2\}, and (3) of the domlnant mode in the arcay for four different values of $t_{l}$. As can be seen, mnving the ferrite tiles off the walls (Increasing $t_{1}$ ) brings in a resonant-like structure at $\sim 2 \mathrm{GHz}$ but has little effect on the attenuation over the rest of the $.5-5.5 \mathrm{CHz}$ band. Because of the beam emittance at the location of the $2.4 \mathrm{CHz}$ array in the debuncher, the value of $t l$. cannot exceed $2 \mathrm{~cm}$. In view of this requirement, and the insensiluvity of the acteruation to variations in $t_{l}$ the ferrite was located $1 \mathrm{~cm}$ from the walts of the array. This location provides for casy installation and removal of the ferrite. The looded arsay is presently wheduled to be installed in the debuncher ring during the last week of April 1985. Teats to evaluate the utility of the ferrite lining should begin sometime in June 1985.

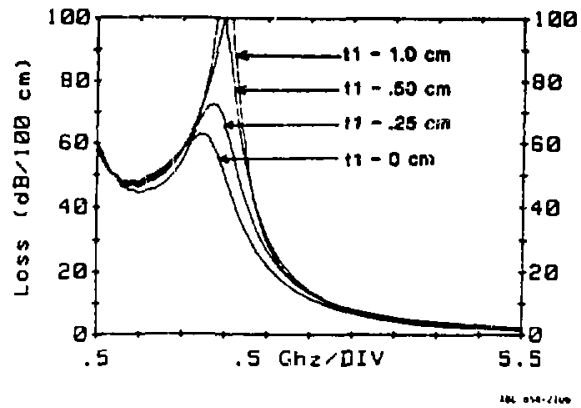

Fig. 4. Attenuation of Dominant Mode in $\mathrm{NZ}-5 !$ Loaded 2-4 $\mathrm{CHz}$ Array.

\section{Beifiencen}

[1] "The Fermileb Antiproten Source Davien Repect." Ferml National Accelerator Laboratory, Febriery 192.

[2] W.C. Barty, Mode Andyals of Fertite Loeded Benm Pipe," Lawrence Barkeley Labortatory, LBLO-953. Auguat. 19a4.

[3] W.C. Barry, "A Broedbend, Automated, 5tripline Technique for the Simulteneous Meceurement of Complex Parmittivity and Permuabillty: Lewrence Barkeley Laboratocy, February 1995. 
This report was done with support from the Department of Energy. Any conclusions or opinions expressed in this report represent solely those of the author(s) and nol necesserily those of The Regenls of the University of California, the Lawrence Berkeley Lahoralory or the Department of Energy.

Keference 10 a company or product name does not imply approval or recommendation of the product by the University of California or the U.S. Department of Energy to the exclusion of athers that may be suitable. 